\title{
RAZÃO E SENTIMENTO NA MORAL DE KANT
}

\author{
Reason and Feeling in Kant's Moral
}

Razón y Sentimiento en la Moral de Kant

JAIR BARBOZA

Resumo: O artigo mostra a tensão entre razão e sentimento na moral de Kant. Trata-se de uma postura que, em verdade, cristaliza uma longa tradição filosófica, desde Platão, para a qual a razão é primária e o querer é secundário. Uma postura a ser revista pelas filosofias da vida.

Palavras-chave: Kant; Razão; Sentimento; Vontade.

Abstract: The article shows the tension between reason and feeling by Kant. This is a position that, in fact, crystallizes a long philosophical tradition, since Plato, to which the reason is primary and the will is secondary. A posture that now begins to be reviewed by de philosophies of life.

Keywords: Kant; Reason; Feeling; Will.

Resumen: El artículo muestra la tensión entre la razón y el sentimiento en la moral de Kant. Se trata de una postura que, en realidad, cristaliza una larga tradición filosófica, desde Platón, para la cual la razón es primaria y el querer es secundario. Una postura para ser revisada por las filosofías de la vida.

Palabras-clave: Kant; Razón; Sentimiento; Voluntad.

I

A tentativa kantiana de fundamentação da ética assenta-se no célebre "imperativo categórico", cuja formulação soa que devemos agir de tal maneira que a máxima da nossa ação se torne uma lei universal. É o princípio da autonomia racional e consciente do agente. $\mathrm{O}$ nome da obra seminal do pensamento ético kantiano porta no nome a sua tarefa. O autor, ao intitulá-la Grundlegung zur Metaphysik der Sitten, mostra no primeiro termo, Grudlegung, "fundamentação", uma espécie de tarefa de construção das bases da ética. Trata-se, pois, de um movimento em direção a um alvo. Todavia, que papel cabe ao sentimento, no seu contraste com a pretensa clareza racional de consciência, em tal empreendimento? As linhas que se seguem indicam esse papel.

\section{II}

Como a própria Fundamentação coloca em seu início, neste mundo e exterior a ele nada é possível considerar como ilimitadamente bom senão uma "boa vontade", livre de quaisquer inclinações ou cálculos utilitários, desvinculada da promessa de recompensas, enfim, uma vontade absolutamente desinteressada e que em si mesma porta o seu supremo valor independente daquilo que ela venha a promover e realizar ou deixar de promover e realizar. Mesmo aquilo que é comumente chamado de qualidade boa pressupõe sempre, para sua chancela, uma boa vontade. Nesse sentido, observa o autor, a moderação das emoções e das paixões, junto com o autodomínio e a calma reflexão, apesar de serem características boas em muitos aspectos e parecerem constituir a boa índole de alguém, ainda assim, sem o princípio de uma boa vontade que as preceda, podem degenerar em coisas más: como no caso do sangue-frio de um facínora. Também se pode aqui pensar, acrescenta Kant, nos dons da fortuna, como a saúde e o bem-estar, alimentadores de ânimo, mas que frequentes vezes desandam em soberba sem uma boa vontade. Portanto, traços bons de um indivíduo sem se pressupor neste uma boa vontade que corrija os excessos não valem como selo de sua boa índole. Só a boa vontade garante as boas qualidades, de tal modo que, mesmo se ela não alcançar seus fins, ainda assim brilha "como uma jóia, como alguma coisa que em si mesma tem o seu pleno valor" (Kant, 2002).

Ora, após ter assim apresentado a boa vontade, Kant passa a argumentar em favor daquilo que propriamente já anuncia uma das principais figuras de pensamento em sua moral, ou seja, a razão é a governante da nossa vontade. Atribui assim um poder de decisão à clarividência racional em face dos sentimentos. Essa razão, na sua modalidade prática, confunde-se ao fim com a própria vontade, tal o poder que as suas máximas têm de legislar sobre esta. Dizer vontade que obedece a leis e dizer razão prática é, no fundo, a mesma coisa. 
Tudo na natureza age segundo leis. Só um ser racional tem a capacidade de agir segundo a representação das leis, isto é, segundo princípios, ou: só ele tem uma vontade. Como para derivar as ações das leis é necessária uma razão, a vontade não é outra coisa senão a razão prática... a vontade é a faculdade de escolher só aquilo que a razão, independentemente da inclinação, reconhece como praticamente necessário, quer dizer como bom. (Kant 2002, p. 47)

A pessoa é racional porque consegue submeter a própria volição à faculdade racional. Consegue combater as próprias inclinações e desse modo afirma a sua autonomia, a sua liberdade, para além do meramente animal em si. Por isso o homem é um fim em si mesmo, não mero meio, ou seja, ele pode autodeterminar-se na convivência com outros seres racionais que, como ele, também serão fins em si mesmos. Isso já abre um abismo entre o homem e o animal, pois este, ao contrário daquele, se submete ao estado patológico ininterrupto das exigências de sua sensibilidade. Nesse sentido, a boa vontade é racional, isto é, colocada em movimento por dever, já que "o conceito de dever contém em si o de boa vontade".

Assim, nota-se um pensamento no qual o sujeito da ação é primariamente consciente de seus atos. A razão detém a força de coerção sobre a comumente inconsciente e assim chamada "natureza animal", isto é, as inclinações e os instintos. Lá se identifica, propriamente dizendo, o caráter de um agente, se é ou não genuinamente ético, na medida em que as suas ações são desinteressadas, ou seja, não se ligam imediatamente às expectativas relacionadas à própria pessoa e sua suposta "natureza”, o que exigiria conservação, tarefa do instinto, ou bem-estar, tarefa de uma inclinação, numa palavra, a felicidade pessoal do "querido eu”. Dessa perspectiva, uma boa ação nada contém de egoístico. Ela é incondicionalmente desinteressada. Nisso, Kant se afasta definitivamente das éticas hedonistas, como se pode encontrar entre os antigos, especialmente em Aristóteles, estóicos e epicuristas. A justificativa do filósofo é que a providência natural teria dotado de maneira muito ruim a sua criatura caso tivesse lhe destinado a razão para executar os fins da felicidade pessoal, que poderiam ser muito melhor alcançadas e com maior segurança pelo instinto. Diz Kant:

Portanto, se a razão não é apta bastante para guiar com segurança a vontade no que respeita aos seus objetos e à satisfação de todas as nossas necessidades... visto que um instinto natural inato levaria com muito maior certeza a este fim, e se, no entanto, a razão nos foi dada como faculdade que deve exercer influência sobre a vontade, então o seu verdadeiro destino deverá ser produzir uma vontade, não só boa quiçá como meio para outra intenção, mas uma vontade boa em si mesma, para o que a razão era absolutamente necessária, uma vez que a natureza de resto agiu em tudo com acerto na repartição das suas faculdades e talentos (Kant 2002, p. 25)

Observe-se: em Kant a razão não é destinada à satisfação de necessidades pois o instinto realizaria muito melhor do que ela esta tarefa! Portanto, se a ela não cabe a felicidade como virtude, resta postular a faculdade racional como algo que direciona para o bem, sem pactuar com as inclinações sensíveis, a natureza animal, logo que até mesmo coage a sensibilidade, desinteressadamente, em vista de uma ação cuja forma é dada pela máxima do ser racional, ou seja, agir de forma a que essa ação se torne uma lei universal. Nesses moldes, se tem uma vontade boa para além de qualquer inclinação.

Curioso é que o imperativo categórico é impossível de ser provado. Talvez, diz Kant, nunca se tenha dado um no mundo - em função do egoísmo colossal do homem mas nem por isso é duvidoso, pois o projeto do filósofo é a fundamentação de uma ética, prescritiva, e, mesmo que a ação boa de um ser naturalmente egoístico seja duvidosa e improvável, tal ética traça o horizonte de um reino dos fins, vale dizer, uma "ligação sistemática de vários seres racionais por meio de leis comuns", em que os seres racionais agem por máximas de boa ação. Um exemplo escolhido por Kant para ilustrar o imperativo é o de uma pessoa dotada de talento que, no entanto, prefere o prazer da comodidade a esforçar-se por desenvolvê-lo, e, dessa forma, evita ampliar as suas disposições em favor da comunidade. Mas, observa o autor, se tal pessoa perguntar sobre a concordância da máxima do seu desleixo com o dever, notará que ela não concorda positivamente com a humanidade como um fim em si mesma. O ser que assim age o faz preterindo a humanidade nele em favor do egoísmo nele, logo, adula o "querido eu”, do qual nenhuma ética pode sair, pois a boa ação refere-se desinteressadamente sempre ao universal. Uma ética privada só se constitui como ética dos interesses, logo, do egoísmo. Mas isto é algo animalesco e não de seres racionais clarividentes.

Com isso, se nota que a ética kantiana pode perfeitamente situar-se na base de um pensamento sócio-histórico, ou seja, do homem como animal essencialmente político, para lembrar o mote aristotélico, que em sociedade deve sempre levar em conta o outro como um fim em si mesmo, visto que o fomento das boas disposições evita, por assim dizer, o holocausto do homem como lobo do homem. Ora, o indivíduo de talento, imerso no gozo da sua comodidade, sem esforçar-se para que seu talento seja convertido em algo favorável à humanidade, não pode querer que isto se transforme em lei universal, pois "como ser racional quer ele necessariamente que todas as suas faculdades se desenvolvam, porque lhe foram dadas e lhe servem para toda a sorte de fins possíveis" (Kant, 2002, p. 61). Em casos assim, o indivíduo deve sacrificar a sua sensibilidade e, mesmo com o desconforto do esforço para desenvolver os seus talentos - por exemplo, numa acade- 
mia de artes - contribuir para que a vontade de todo ser racional deva ser uma vontade legisladora universalmente; e isto apenas se concretiza se a máxima da sua ação não for racionalmente contraditória, contra o dever, isto é, não pode ser interessada como seria a máxima desse indivíduo talentoso caso ele permanecesse no desleixo, largado ao sabor do gozo de sua sensibilidade.

Ora, é justamente esse procedimento contra a sensibilidade que prova uma liberdade da razão em face do patológico, justamente a autonomia do sujeito racional: sua capacidade de submeter o querer ao dever. Ao contrário do animal, que não consegue libertar-se de móbiles sensuais e instintivos.

Em Kant, portanto, tem-se uma ética para seres racionais, no sentido que estes são pessoas. Isto exclui, pelo menos de maneira imediata, os animais. Para o filósofo só a natureza racional existe como fim em si mesma. Não há aqui a inclusão dos seres irracionais e sensíveis, pois, segundo o filósofo, eles são Sache, coisas.

Os seres cuja existência depende não em verdade da nossa vontade, mas da natureza, têm, contudo, se são seres irracionais, apenas um valor relativo como meios e por isso se chamam coisas, ao passo que os seres racionais se chamam pessoas (Kant, 2002, p. 68)

"Meios": isto obviamente abre a possibilidades de uso dos mesmos. Naturalmente Kant não era um insensível a ponto de pensar os animais como meros instrumentos, todavia, o seu pensamento abre, nos dias de hoje, a polêmica sobre a justificativa ou não de animais em experimentos científicos, pois esses mesmos animais sofrem, sentem dor, e, não seria o caso de se pensar ali numa possível dignidade perdida por eles? Nossa comum dignidade? Uma comunidade de seres sensíveis? Porém isto não cabe no pensamento kantiano, pois o sensível é patologicamente determinado, relativo, sem abertura para o necessariamente universal.

\section{III}

Nesses moldes vemos em Kant todas as consequências de uma longa tradição ocidental de pensamento, inaugurada pelo racionalismo platônico que sentenciava que só entraria na Academia quem dominasse os conhecimentos matemáticos, fonte privilegiada de acesso à verdade nos arquétipos eternos, as Idéias. Esse poder da razão, faculdade soberana do homem e que o define e aparta dos demais seres, é a mesma que levará Descartes, na aurora da modernidade, a dizer que não existe erro maior que considerar que a nossa alma tem a mesma natureza que a animal. Descartes inclusive postula uma espécie de matemática universal, retomando Platão, para dar conta do segredo e verdade do mundo, essencialmente apreensível por via de números e formas geométricas. Noutros termos, o querer, o inconsciente é secundário, e a clarividência da razão é primária. É com ela que o homem, diz este inaugurador da filosofia moderna, se torna como que senhor e possuidor da natureza. Trata-se de um projeto que deságua no iluminismo e em sua relação imperial com a natureza, num projeto que hoje em dia, já tarde, começa a ser revisto, para o que as filosofias da vontade inconsciente de Schopenhauer e Nietzsche, e nos seus passos, a psicologia de Jung e a psicanálise de Freud, decerto foram decisivos, ao mostrarem que a consciência é apenas uma crosta do inconsciente desejante e irracional e a razão é um mero instrumento secundário de sobrevivência de um organismo extremamente complexo. Mas esta é uma história que pretendo desenvolver em outra oportunidade.

\section{Referências}

Kant, I. (1998). Werke in Sechs Baenden. Hrsg. Wilhelm Weischedel. Darmstadt: Wiss. Buchges.

Kant, I. (2002). Fundamentação da metafísica dos costumes (Coleção Textos Filosóficos) Lisboa: Edições 70. (Originalmente publicado em 1785).

Jair Barboza - Professor do Curso de Filosofia e do Programa de Mestrado em Filosofia da Pontifícia Universidade Católica do Paraná. Possui Doutorado em Filosofia pela Universidade de São Paulo (USP) e Pós-Doutorado pela Universitaet Frankfurt e Universitaet Hamburg. Endereço para correspondência: PPGF (Programa de Pós-Graduação em Filosofia) - PUC/PR. Rua Imaculada Conceição, nº 1155, Bloco CTCH. CEP 80.215-901 - Curitiba, PR. Email: jbarboza@gmx.net

Recebido em 09.03.09 Aceito em 15.10.09 